\title{
Inflammatory Cytokine TSLP Stimulates Platelet Secretion and Potentiates Platelet Aggregation via a TSLPR-Dependent PI3K/ Akt Signaling Pathway
}

\author{
Jangchuan Donga, Jing Lin ${ }^{\mathrm{b}}$ Boyuan Wang ${ }^{\mathrm{b}}$ Shaolin $\mathrm{He}^{\mathrm{b}} \quad$ Chun Wu $^{\mathrm{b}}$ \\ Kishan Kumar Kushwaha ${ }^{b}$ Nilesh Mohabeer ${ }^{b}$ Yousu Su ${ }^{c}$ Hongcheng Fang ${ }^{c}$ \\ Kai Huang ${ }^{b}$ Dazhu Li ${ }^{b}$ \\ aDepartment of emergency, The Second Affiliated Hospital of Chongqing Medical University, \\ Chongqing; 'Department of Cardiology, Institute of Cardiovascular Diseases, Union Hospital, Tongji \\ Medical College, Huazhong University of Science and Technology, Wuhan; 'Department of Cardiology, \\ Shenzhen Sixth People's Hospital (Nanshan Hospital), Huazhong University of Science and Technology, \\ Union Shenzhen Hospital, Shenzhen, China
}

\section{Key Words}

Thymic stromal lymphopoietin • Platelet activation • Thrombus formation • PI3K/Akt signaling

\begin{abstract}
Aims: Thymic stromal lymphopoietin (TSLP) plays an important role in inflammatory diseases and is over-expressed in human atherosclerotic artery specimens. The present study investigated the role of TSLP in platelet activation and thrombosis models in vitro and in vivo, as well as the underlying mechanism and signaling pathway. Methods and Results: Western blotting and flow cytometry demonstrated that the TSLP receptor was expressed on murine platelets. According to flow cytometry, platelet stimulation with TSLP induced platelet degranulation and integrin $\alpha \operatorname{IIb} \beta 3$ activation. A TSLPR deficiency caused defective platelet aggregation, defective platelet secretion and markedly blunted thrombus growth in perfusion chambers at both low and high shear rates. TSLPR KO mice exhibited defective carotid artery thrombus formation after exposure to $\mathrm{FeCl}_{3}$. TSLP increased Akt phosphorylation, an effect that was abrogated by the PI3K inhibitors wortmannin and LY294002. The PI3K inhibitors further diminished TSLP-induced platelet activation. TSLP-mediated platelet degranulation, integrin $\alpha I I b \beta 3$ activation and Akt phosphorylation were blunted in platelets that lacked the TSLP receptor. Conclusion: This study demonstrated that the functional TSLPR was surfaceexpressed on murine platelets. The inflammatory cytokine TSLP triggered platelet activation and thrombus formation via TSLP-dependent PI3K/Akt signaling, which suggests an important role for TSLP in linking vascular inflammation and thrombo-occlusive diseases.
\end{abstract}

Copyright (C) 2015 S. Karger AG, Basel

Dr. Dazhu Li

KARGER 125
Department of Cardiology, Institute of Cardiovascular Diseases, Union Hospital, Tongji Medical College, Huazhong University of Science and Technology, 1277 Liberation Avenue, Wuhan (China)

Tel. +86-027-85726011, E-Mail lidazhuhp@sohu.com 
Dong et al.: TSLP Triggers Platelet Activation

\section{Introduction}

Platelet adhesion and subsequent aggregation at the vascular injury site are key events required for hemostasis [1, 2]; however, they are also critical for the development of acute thrombotic occlusion at regions of atherosclerotic plaque rupture, which reflect the major pathophysiological mechanism underlying ischemic diseases, such as myocardial infarction or stroke [3]. Platelet activation is induced by platelet agonists, such as ADP, collagen or thrombin [4]. The agonists lead to platelet degranulation, shape changes, integrin $\alpha \operatorname{IIb} \beta 3$ activation and adhesion to the vascular wall [5]. Apart from thrombosis, there is increasing evidence that platelets are critically involved in the pathogenesis of inflammatory diseases [6, 7] via interactions with a variety of inflammatory cells [8]. During inflammatory stimulation, platelets rapidly adhere to the endothelium or subendothelial extracellular matrix at sites of vascular endothelial injury [6].

Cytokines, including tumor necrosis factors, interleukins, interferons, and colony stimulating factors, are produced by macrophages, T-cells and monocytes, as well as platelets, endothelial cells and vascular smooth muscle cells. Additionally, they are central players in vascular inflammation processes via the recruitment of leukocytes, which leads to the progression of atherosclerosis and plaque destabilization [9]. Accumulating literature suggests a delicate role of cytokines in atherothrombosis, and members of the cytokine family have been shown to activate platelets via their receptors $[10,11]$. However, the exact signaling mechanisms of platelet activation by inflammatory cytokines remain unknown.

Thymic stromal lymphopoietin (TSLP) is a newly identified interleukin-7-like cytokine, which was originally isolated from a murine thymic stromal cell line [12] and characterized as a lymphocyte growth factor [13]. Substantial progress has been made in the understanding of the biological responses mediated by TSLP because this cytokine was first cloned. Previous studies have demonstrated TSLP has important actions in inflammation and allergy diseases, including rheumatoid arthritis, colonic inflammation and asthma [1420]. In general, TSLP is produced by epithelial cells and epidermal keratinocytes, and recent studies have demonstrated that several inflammatory cells, including dendritic cells $\left(\mathrm{DC}_{\mathrm{S}}\right)$, smooth muscle cells, and cancer or cancer-associated cells, also express TSLP [19, 21-25]. Recently, we demonstrated that TSLP could be induced to express in vascular endothelial and smooth muscle cells by angiotensin II and oxidized-low-density lipoprotein [26] and over-expressed in human atherosclerotic artery specimens [27], which indicated that TSLP/ TSLPR might play roles in atherosclerosis. Therefore, TSLP is not only associated with inflammatory and allergy diseases but also plays important roles in atherosclerosis, which has been linked to platelet activation and the probability of thrombosis [28-31].

TSLP activates its unique receptor TSLPR, which is expressed in numerous cells, which predominantly include a variety of hematopoietic cells, such as T cells, B cells, monocytes and $\mathrm{DC}_{\mathrm{S}}[21,22]$. Several groups have demonstrated that TSLPR participated in the development of inflammation and tumors [23-25]. Signaling followed by an activation of TSLPR by TSLP has been shown to involve phosphatidylinositide 3-kinase (PI3K) and its downstream effector Akt [32, 33]. Platelets are also derived from megakaryocytes of hematopoietic cells and are known to be the major players in atherothrombosis pathogenesis [7]. Whether platelets express functional TSLPRs and whether the inflammatory cytokine TSLP plays a role in platelet function are largely unknown. In our preliminary study, we demonstrated that the TSLPR was surface-expressed on human platelets. We also demonstrated that compared with the control group, platelets expressed higher levels of TSLPRs in patients with acute coronary syndrome; [34] thus, we thought that the TSLPR might play important roles in mediation of platelet activation in this thrombotic disease. However, the exact role and the mechanism of the TSLP/TSLPR signaling pathway in platelet activation and thrombosis formation remain unknown.

The purpose of this study was to determine whether murine platelets expressed TSLPR and the functional significance of TSLP for platelet activation. Moreover, the role of PI3K/ Akt signaling that is the downstream of the TSLP/TSLPR in the regulation of TSLP-sensitive 
Dong et al.: TSLP Triggers Platelet Activation

platelet functions was addressed, and the underlying mechanism of TSLP-induced platelet activation and thrombosis was examined.

\section{Materials and Methods}

\section{Ethics}

This study was approved by the Ethics Committee of Tongji Medical College, Huazhong University of Science and Technology, China. For research, that involved human participants, written informed consent was obtained in accordance with the Declaration of Helsinki.

Animals. TSLPR knockout (TSLPR KO) mice (on C57BL/6 background) (TSLPR $\%$ ) were kindly supplied by Professor Nicola L. Harris (Swiss Vaccine Research Institute, Lausanne, Switzerland) with the permission of Dr James N. Ihle (St. Jude Children's Research Hospital, USA). Wild-type (WT) C57BL/6 mice (TSLPR ${ }^{+/}$) were obtained from Peking University. The investigation conforms to the Guide for the Care and Use of Laboratory Animals published by the US National Institutes of Health (NIH Publication, 8th Edition, 2011).

\section{Human platelet preparation}

Human platelets were isolated as previously described [35]. Blood from healthy volunteers was collected in ACD-buffer and centrifuged at $200 \mathrm{~g}$ for 20 minutes. The obtained platelet-rich plasma was added to modified Tyrode-HEPES buffer ( $137 \mathrm{Mm} \mathrm{NaCl}, 2.8 \mathrm{mM} \mathrm{KCL}, 12 \mathrm{mM} \mathrm{NaHCO} 3,5 \mathrm{mM}$ glucose, $0.4 \mathrm{mM}$ Na2HPO4, $10 \mathrm{mM}$ HEPES, $0.1 \%$ bovine serum albumin, $\mathrm{pH}$ 6.5). After centrifugation at $900 \mathrm{~g}$ for 10 minutes and the removal of the supernatant, the resulting platelet pellet was resuspended in Tyrode-HEPES buffer ( $\mathrm{pH} 7.4$, supplemented with $1 \mathrm{mM} \mathrm{CaCl}$ ).

Mouse platelet preparation and transfusion

Mice (8-10 weeks old) were anesthetized by pentobarbital $(100 \mathrm{mg} / \mathrm{kg})$ and bled from the retroorbital plexus with the use of heparin-coated glass capillary tubes. Blood was collected into tubes that contained $3 \%$ ACD (1/9 vol/vol). Platelet rich plasma (PRP) was obtained by centrifugation at $300 \mathrm{~g}$ for 7 minutes. The PRP was subsequently centrifuged at $640 \mathrm{~g}$ for 5 minutes to pellet the platelets. After two further washing steps, the pellet of the washed platelets was resuspended in modified Tyrode-HEPES buffer (pH 7.4, supplemented with $1 \mathrm{mM} \mathrm{CaCl} 2$ ). Platelets from the suspension were then diluted with PBS to a concentration of $200 \times 10^{6}$ platelets in $0.15 \mathrm{~mL}$ and transfused via jugular vein into recipient mice immediately prior to TSLP or saline administration.

\section{Western blot analysis}

Platelets or DCs were resuspended in lysis buffer that contained a protease inhibitor cocktail (SigmaAldrich). Following a 30 minute centrifugation with $16,000 \mathrm{~g}$ at $4^{\circ} \mathrm{C}$, the supernatant was collected for Bradford assay (Biorad) to determine the protein concentration. After boiling the samples for 10 minutes at $95^{\circ} \mathrm{C}$ in Roti@-Load1 (Roth), the cell lysates were separated by $10 \%$ SDS-PAGE and blotted on nitrocellulose or PVDF membrane. The membranes were blocked for 1 hour with 10\% nonfat-milk or 5\% BSA in TBS$0.1 \%$ Tween 20 (TBST). The membranes were subsequently incubated with primary antibody against TSLP (1:500; eBioscience, USA) or Thr308 or Ser473 pAkt (1:1000; Cell Signaling) at $4^{\circ} \mathrm{C}$ overnight. After washing with TBST, the blots were incubated with the adequate secondary antibody conjugated with horse radish peroxidase (HRP) (1:2000; Cell Signaling) for at least 2 hours. Antibody binding was detected with the ECL detection reagent, and the bands were quantified with Quantity One Software (Biorad).

\section{Flow cytometry}

P-selectin expression was measured using an FITC-labeled mouse anti-human P-selectin monoclonal antibody (BD Biosciences). Activated integrin $\alpha \operatorname{Ilb} \beta 3$ was quantified through the binding of the FITClabeled mouse anti-human monoclonal antibody PAC-1 (BD Biosciences). The platelets were activated using recombinant human or murine TSLP (R\&D Systems). TSLPR expression was analyzed using a PE-conjugated mouse anti-human TSLP receptor antibody (eBioscience, USA) or a PE-conjugated anti-mouse TSLPR antibody (eBioscience, USA). Corresponding isotype controls were used for each antibody. A two-color 
Dong et al.: TSLP Triggers Platelet Activation

analysis of mouse platelet activation was conducted using fluorophore-labeled antibodies for P-selectin expression (Wug.E9-FITC) (BD Biosciences) and the active form of $\alpha \operatorname{Ib} \beta 3$ integrin (JON/A-PE) (BD) as previously described [6].

\section{Aggregometry}

Light transmission aggregometry (Chrono-Log Corp, USA Havertown, PA) was performed with isolated human platelets $(2.5 \times 105 / \mu \mathrm{l})$. After calibration, the agonists were added at the indicated concentrations, and aggregation was measured for 6 minutes with a stir speed of $1000 \mathrm{rpm}$ at $37^{\circ} \mathrm{C}$. The extent of aggregation was quantified as the $\%$ of light transmission. The data analysis was performed with AGGRO/LINK8 software (Chrono-Log).

\section{Dense-granule secretion}

ATP release was monitored in parallel with platelet aggregation. To examine the effects of TSLP on ATP release, washed platelets were incubated with TSLP $(200 \mathrm{ng} / \mathrm{ml})$ or thrombin $(0.01 \mathrm{U} / \mathrm{ml})$, and ATP in the supernatant was measured by the addition of luciferin-luciferase reagent. Quantification was performed using the ATP standard.

Murine PRP was incubated for 30 minutes at $37^{\circ} \mathrm{C}$ with $3 \mathrm{H}$-serotonin $(2 \mu \mathrm{Ci}[0.074 \mathrm{MBg}] / \mathrm{mL})$, washed once with HEN buffer, and then resuspended in HEPES-Tyrode buffer that contained $1 \mu \mathrm{M}$ imipramine and $1 \mathrm{mM} \mathrm{CaCl}_{2}$. The platelets were stimulated with thrombin for 6 minutes at $37^{\circ} \mathrm{C}$. The reactions were stopped with an equal volume of $0.1 \mathrm{M} \mathrm{EDTA} / 2 \%$ formaldehyde and centrifuged for 5 minutes at $10,000 \mathrm{~g} .{ }^{3} \mathrm{H}$ in the supernatants and pellets was counted, and the percentage of 5-HT secretion was defined as the agonistrelated increase in extracellular ${ }^{3} \mathrm{H}$ divided by the total intracellular ${ }^{3} \mathrm{H}$ at the start of the experiment.

\section{Perfusion flow chamber assays}

The ex vivo perfusion flow chamber thrombosis model was performed at high $\left(1800 \mathrm{~s}^{-1}\right)$ and low $\left(600 \mathrm{~s}^{-1}\right)$ shear rates, as described in previous studies.[36] We used the rectangular parallel plate flow chamber (Glycotech, Rockville, MD). Briefly, rectangular $(0.1 \times 1 \mathrm{~mm})$ glass capillary microslides were coated with $100 \mu \mathrm{g} / \mathrm{mL}$ type-I collagen fibrils (Sigma-Aldrich, Saint Louis, USA) overnight at $4^{\circ} \mathrm{C}$. Murine blood was perfused over the collagen-coated surface under a controlled flow rate with the use of a syringe pump (Harvard Apparatus, Holliston, MA). The blood was perfused for 4 minutes followed by 2 minutes of perfusion with a rinsing buffer ( $\mathrm{NaCl} 130 \mathrm{mM}, \mathrm{KCl} 2 \mathrm{mM}, \mathrm{NaHCO} 312 \mathrm{mM}, \mathrm{CaCl}_{2} 2.5 \mathrm{mM}, \mathrm{MgCl}_{2} 0.9 \mathrm{mM}$, glucose $5 \mathrm{mM}, \mathrm{pH} \mathrm{7.4)}$ at $37^{\circ} \mathrm{C}$. Ex vivo thrombus formation was monitored using WT and TSLPR KO platelets in the concentration of $200 \mathrm{ng} / \mathrm{ml}$ TSLP. Platelet aggregation and thrombus formation were recorded in real-time over the course of perfusion under a bright field with a Zeiss Axiovert 135 inverted microscope and computer (IBM IntelliStation Z Pro) using the Slidebook program (Intelligent Imaging Innovations).

Ferric chloride carotid artery thrombosis model[37]

The WT and TSLPR KO mice (8-10 weeks old) were anesthetized via the administration of pentobarbital $(100 \mathrm{mg} / \mathrm{kg})$ and secured supine under a dissecting microscope. The right carotid artery was exposed by blunt dissection. A miniature Doppler flow probe was placed on the surface of the artery, and the flow was measured to ensure proper placement of the probe. A 2.5 -mm strip of filter paper was saturated with $10 \%$ $\mathrm{FeCl}_{3}$ (Sigma-Aldrich) and applied to the adventitial surface of the exposed artery for 2.50 minutes to induce vessel damage. The groups comprised the WT, TSLPR KO and TSLPR KO+WT washed platelet transfusion groups. Saline or TSLP $(200 \mathrm{ng} / \mathrm{ml})$ was injected into the jugular vein of the mice prior to the initiation of the carotid artery injury. The blood flow in the carotid artery following the $\mathrm{FeCl}_{3}$-induced injury was monitored until complete vessel occlusion was observed. Arterial flow rate was monitored for 30 minutes.

\section{Statistical analysis}

The data are presented as the means \pm SD or SEM, and $\mathrm{n}$ represents the number of experiments. The data were analyzed by Student t-test or one-way ANOVA coupled with the Student-Newman-Keuls multiple comparison tests or one-way ANOVA with Dunnets post-hoc test. Differences were considered statistically significant if $\mathrm{P}<0.05$. All statistical analyses were performed with the SPSS 17.0 statistical package. 


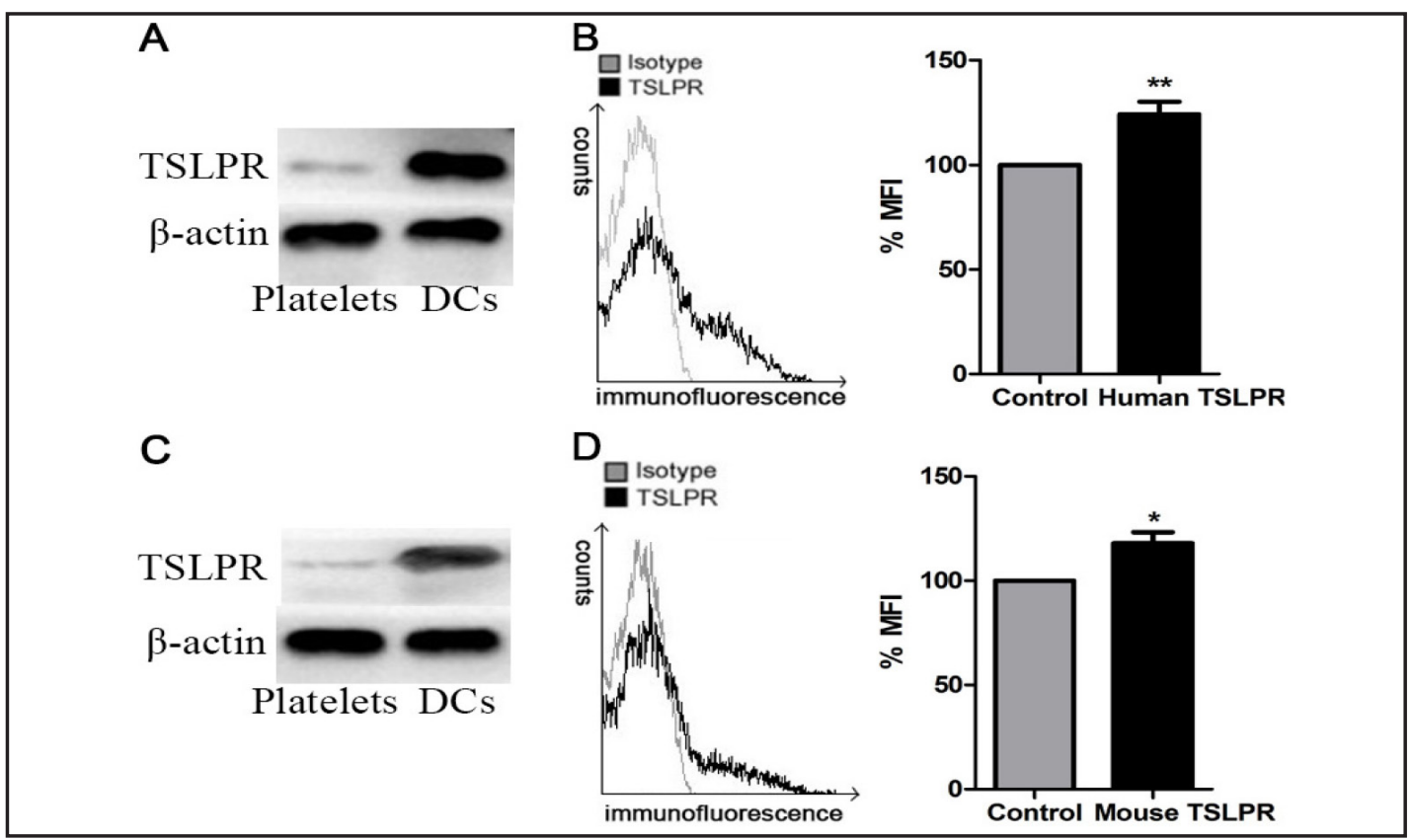

Fig. 1. TSLPR protein expression in human and murine platelets. A\&B. Representative western blot of TSLPR in human platelets $(n=4)$. $D_{S}$ served as a positive control, and $\beta$-actin served as a loading control. Arithmetic means \pm SEM $(n=4)$ and representative overlay of flow cytometry of TSLPR membrane expression in human platelets. ${ }^{* *}(\mathrm{p}<0.01)$ indicates a significant difference. C\&D. Representative western blot of TSLPR in murine platelets $(n=4)$. Arithmetic means \pm SEM $(n=4)$ and representative overlay of flow cytometry of TSLPR membrane expression in murine platelets. ${ }^{*}(\mathrm{p}<0.05)$ indicates a significant difference.

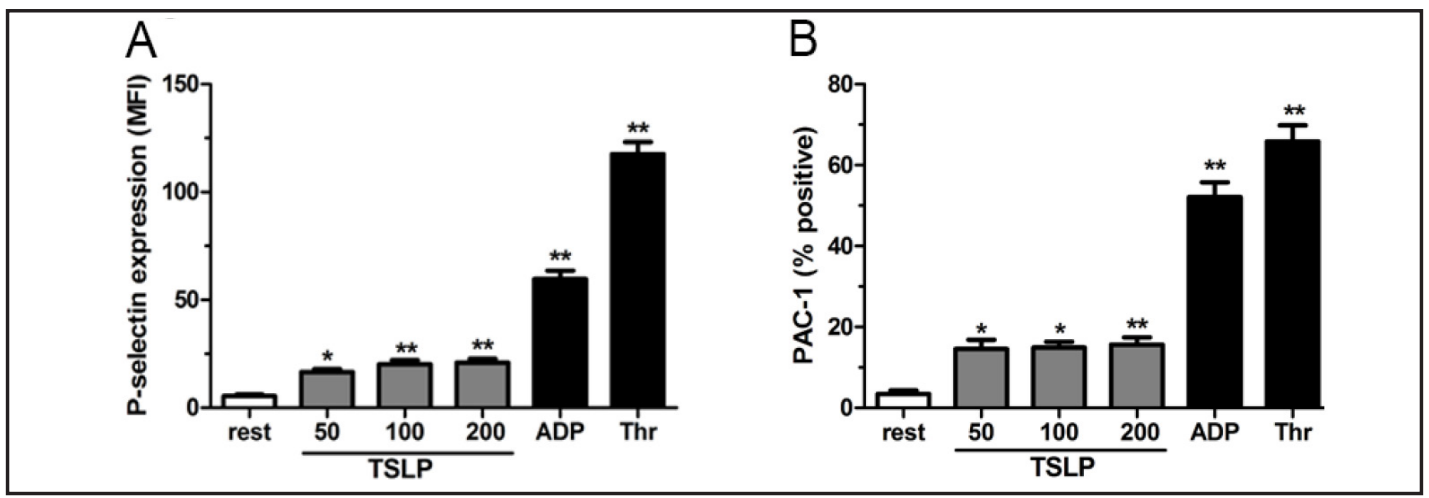

Fig. 2. Expression of P-selectin and activated integrin $\alpha \operatorname{IIb} \beta 3$ in human platelets after TSLP treatment. A. Flow cytometry of P-selectin expression in human platelets after TSLP stimulation (ng/ml). ADP (5 $\mu \mathrm{M})$ and thrombin $(0.01 \mathrm{U} / \mathrm{ml})$ served as positive controls. Arithmetic means \pm SEM $(n=8)$ are shown. ${ }^{*}(p<0.05)$ and $* *(p<0.01)$ indicate significant differences compared with resting platelets. B. Flow cytometry of activated integrin $\alpha \operatorname{IIb} \beta 3$ (PAC-1) expression in human platelets after TSLP stimulation (ng/ml). ADP (5 $\mu \mathrm{M})$ and thrombin $(0.01 \mathrm{U} / \mathrm{ml})$ served as positive controls. Arithmetic means \pm SEM $(\mathrm{n}=8)$ are shown. ${ }^{* *}(\mathrm{p}<0.01)$ indicates a significant difference.

\section{Results}

TSLPR protein expression in human and murine platelets

To investigate whether the TSLPR is expressed on human platelets, we examined it via flow cytometry and western blot. Western blotting and flow cytometry of human and murine platelets indicated that the TSLPR was expressed on platelets (Fig. 1). Because $\mathrm{DC}_{\mathrm{S}}$ have been well known for TSLPR expression [21, 22, 25], $\mathrm{DC}_{S}$ served as positive control. 


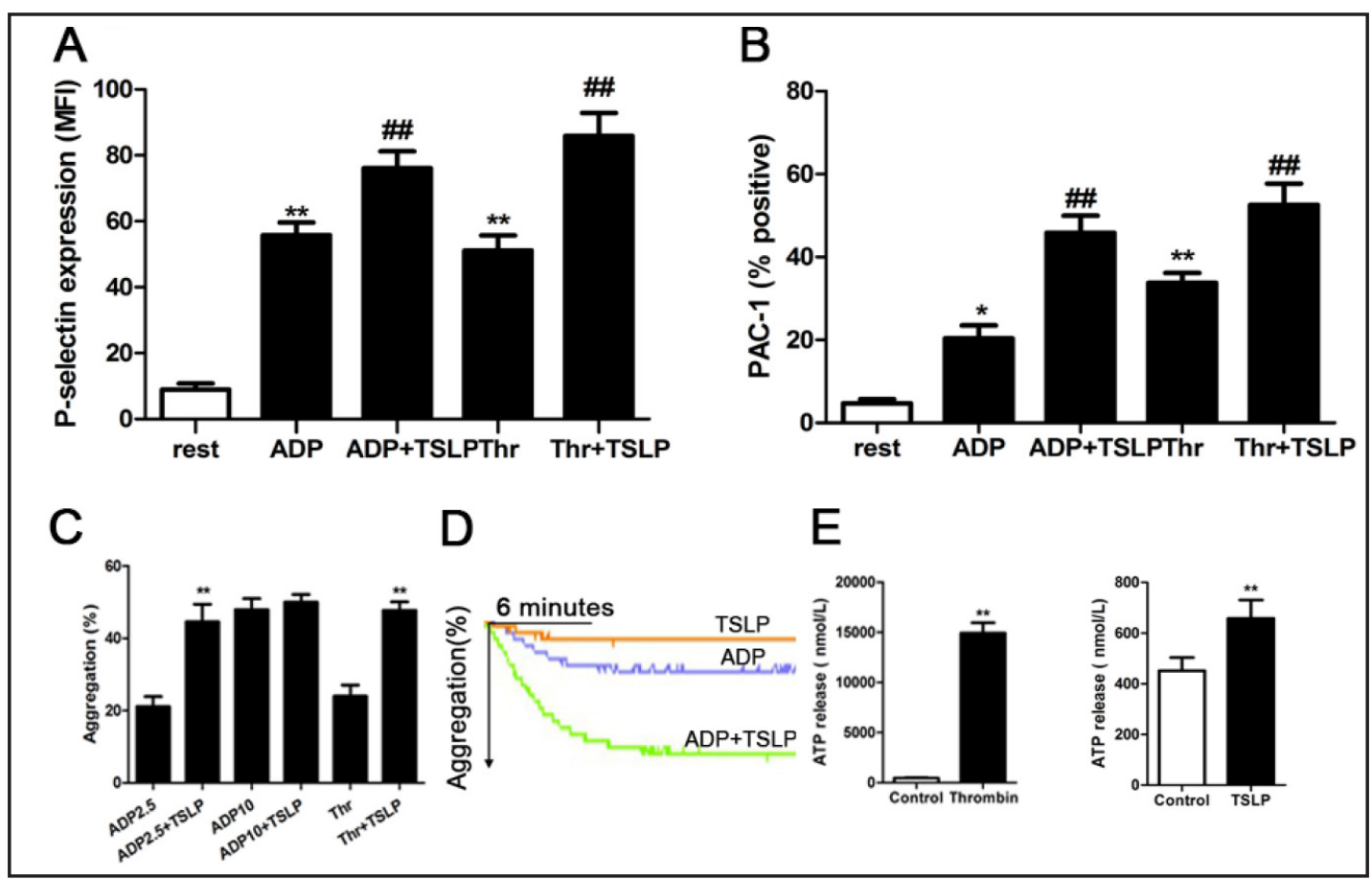

Fig. 3. Effects of TSLP on potentiating platelet degranulation, integrin $\alpha \operatorname{IIb} \beta 3$ activation and aggregation in response to different agonists. TSLP stimulates platelet secretion of dense granules. A, B. Flow cytometry of P-selectin (left) and activated integrin $\alpha \mathrm{IIb} \beta 3$ (PAC-1; right) expression in human platelets after preincubation with or without TSLP $(200 \mathrm{ng} / \mathrm{ml})$ followed by stimulation with ADP $(2.5 \mu \mathrm{M})$ or thrombin $(0.001 \mathrm{U} /$ $\mathrm{ml}$; Thr $)$. Arithmetic means \pm SEM $(\mathrm{n}=6)$ are shown. ${ }^{*}(\mathrm{p}<0.05)$ and ${ }^{* *}(\mathrm{p}<0.01)$ indicate significant differences compared with resting platelets; $\# \#(p<0.01)$ indicates significant differences compared with platelets pretreated with Tyrode buffer instead of TSLP. C. Arithmetic means \pm SEM $(n=6)$ of platelet aggregation after preincubation with or without TSLP $(200 \mathrm{ng} / \mathrm{ml})$ followed by stimulation with ADP $(2.5 \mu \mathrm{M}$ and $10 \mu \mathrm{M})$ or thrombin $\left(0.001 \mathrm{U} / \mathrm{ml}\right.$; Thr) are shown. ${ }^{* *}(\mathrm{p}<0.01)$ indicates a significant difference compared with platelets pretreated with Tyrode buffer instead of TSLP. D. Representative tracings of platelet aggregation after stimulation with TSLP $(200 \mathrm{ng} / \mathrm{ml})$ and after preincubation with or without TSLP followed by stimulation with ADP $(2.5 \mu \mathrm{M})$. E. Human washed platelets were incubated with TSLP $(200 \mathrm{ng} / \mathrm{ml})$ or thrombin $(0.01 \mathrm{U} /$ $\mathrm{ml}$ ). The release of ATP into the platelet supernatant was determined by a luciferin/luciferase assay. Values represent the mean $\pm \operatorname{SEM}(\mathrm{n}=10),{ }^{* *}(\mathrm{p}<0.01)$ compared with the control.

Expression of P-selectin and activated integrin $\alpha I I b \beta 3$ in human platelets after TSLP treatment

It is unknown whether TSLP can directly affect platelet activation or indirectly affect the platelet activation process via actions on other molecules in blood plasma. Therefore, we examined P-selectin and active integrin $\alpha \operatorname{Ib} \beta 3$ expression on washed platelets. According to the flow cytometric analysis, the stimulation of platelets in vitro with TSLP (50, 100 and $200 \mathrm{ng} / \mathrm{ml}$ ) significantly enhanced the expression of P-selectin ( $200 \mathrm{ng} / \mathrm{ml}: 20.9 \pm 5.1 \mathrm{vs.} 5.4$ $\pm 2.4, \mathrm{p}<0.01)$ and activated integrin $\alpha \operatorname{Ilb} \beta 3(200 \mathrm{ng} / \mathrm{ml}: 15.6 \pm 5.1$ vs. $3.4 \pm 2.5, \mathrm{p}<0.01)$ at the platelet surface (Fig. $2 \mathrm{~A}, \mathrm{~B}$ ). In the previously described experiments, stimulation with low dose ADP $(5 \mu \mathrm{M})$ or thrombin $(0.01 \mathrm{U} / \mathrm{ml})$ was used as a positive control. However, the extent of platelet stimulation triggered by TSLP was significantly weaker compared with the stimulation after treatment with ADP or thrombin (Fig. 2 A,B).

Effects of TSLP on the potentiation of platelet degranulation, integrin $\alpha I I b \beta 3$ activation and aggregation in response to different agonists

TSLP potentiated platelet activation in response to low dose ADP stimulation (P-selectin: $76.2 \pm 12.4$ vs. $55.8 \pm 9.4$, p < 0.01; PAC- $1: 45.9 \pm 10.0$ vs. $20.4 \pm 7.6, \mathrm{p}<0.01$ ) and also exhibited 


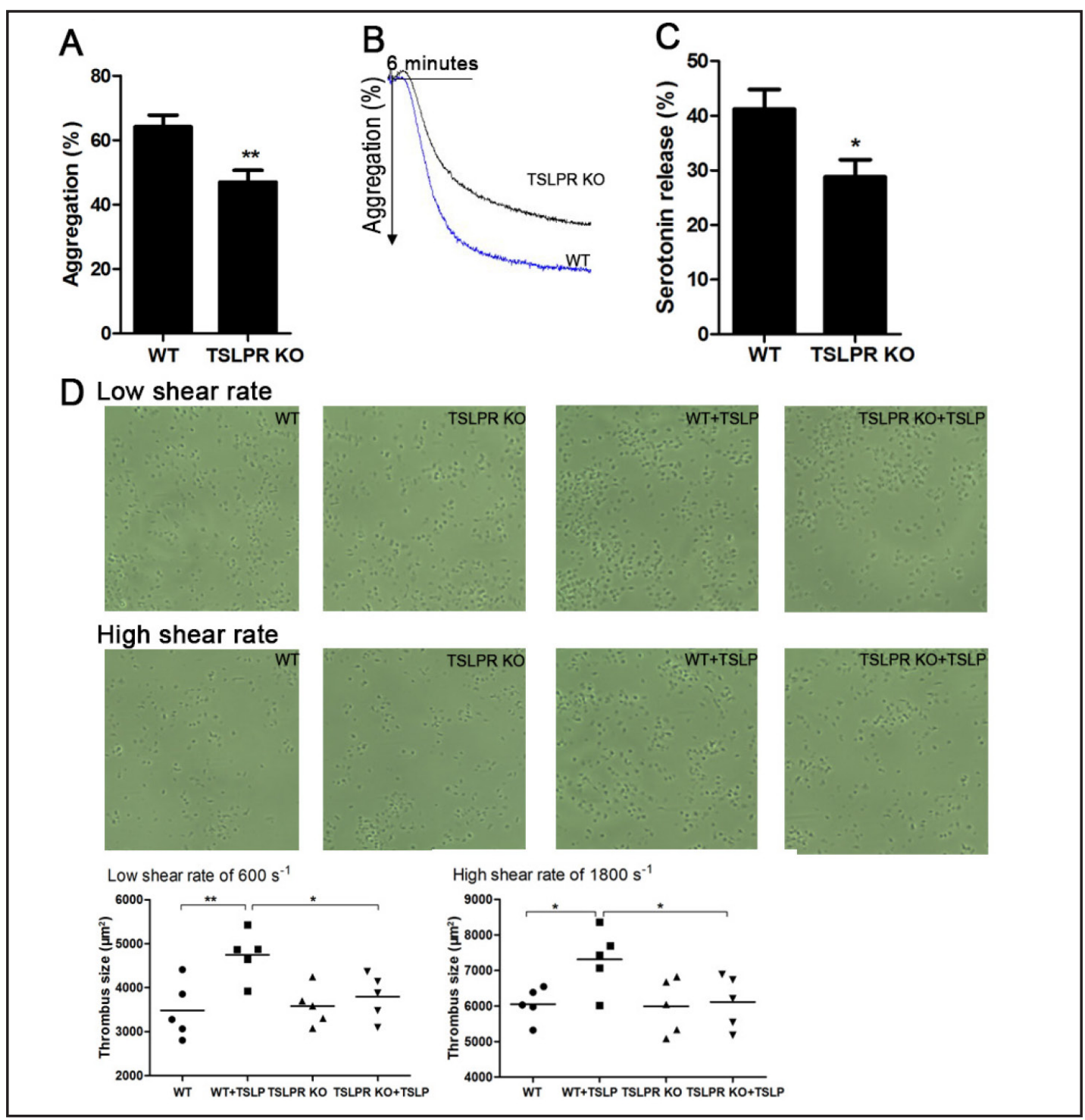

Fig. 4. Effects of TSLPR deficiency on platelet aggregation and secretion and in vitro thrombus formation under flow. A. Arithmetic means \pm SEM ( $n=5)$ of platelet aggregation after preincubation with TSLP (200 ng/ $\mathrm{ml})$ followed by stimulation with thrombin $(0.01 \mathrm{U} / \mathrm{ml}$; Thr $)$ are shown. ${ }^{* *}(\mathrm{p}<0.01)$ indicates a significant difference compared with WT platelets. B. Representative tracings of platelet aggregation after preincubation with TSLP $(200 \mathrm{ng} / \mathrm{ml})$ followed by stimulation with thrombin $(0.01 \mathrm{U} / \mathrm{ml}$; Thr $)$. C. Arithmetic means \pm SEM $(n=5)$ of platelet serotonin release after preincubation with TSLP (200 $\mathrm{ng} / \mathrm{ml})$ followed by stimulation with thrombin $(0.01 \mathrm{U} / \mathrm{ml}$; Thr $)$ are shown. ${ }^{*}(\mathrm{p}<0.05)$ indicates a significant difference compared with WT platelets. D. Ex vivo thrombus formation was monitored on type-I collagen at $600 \mathrm{~s}^{-1}$ or $1800 \mathrm{~s}^{-1}$ using WT and TSLPR KO platelets in $200 \mathrm{ng} / \mathrm{ml} \mathrm{TSLP.} \mathrm{Platelet} \mathrm{aggregation} \mathrm{and} \mathrm{thrombus} \mathrm{formation} \mathrm{were} \mathrm{recorded} \mathrm{in}$ real-time over the course of perfusion under a bright field with a Zeiss Axiovert 135 inverted microscope and computer using the Slidebook program. Surface coverage and thrombus size were calculated from the light microscope images using Image J software. Values represent the mean \pm SEM. ${ }^{*}(p<0.05)$ and ${ }^{* *}(p<0.01)$ indicate significant differences.

a potentiating effect in response to stimulation with low doses of thrombin (P-selectin: $85.9 \pm 17.1$ vs. $51.1 \pm 11.2, \mathrm{p}<0.01$; PAC-1: $52.6 \pm 12.5$ vs. $33.8 \pm 5.9, \mathrm{p}<0.01$ ) (Fig. 3 A,B) To determine whether TSLP directly induces platelet activation, we used washed human platelets to examine the effects of TSLP on platelet aggregation. TSLP alone induced a weak platelet aggregation; however, it significantly amplified aggregation following stimulation 


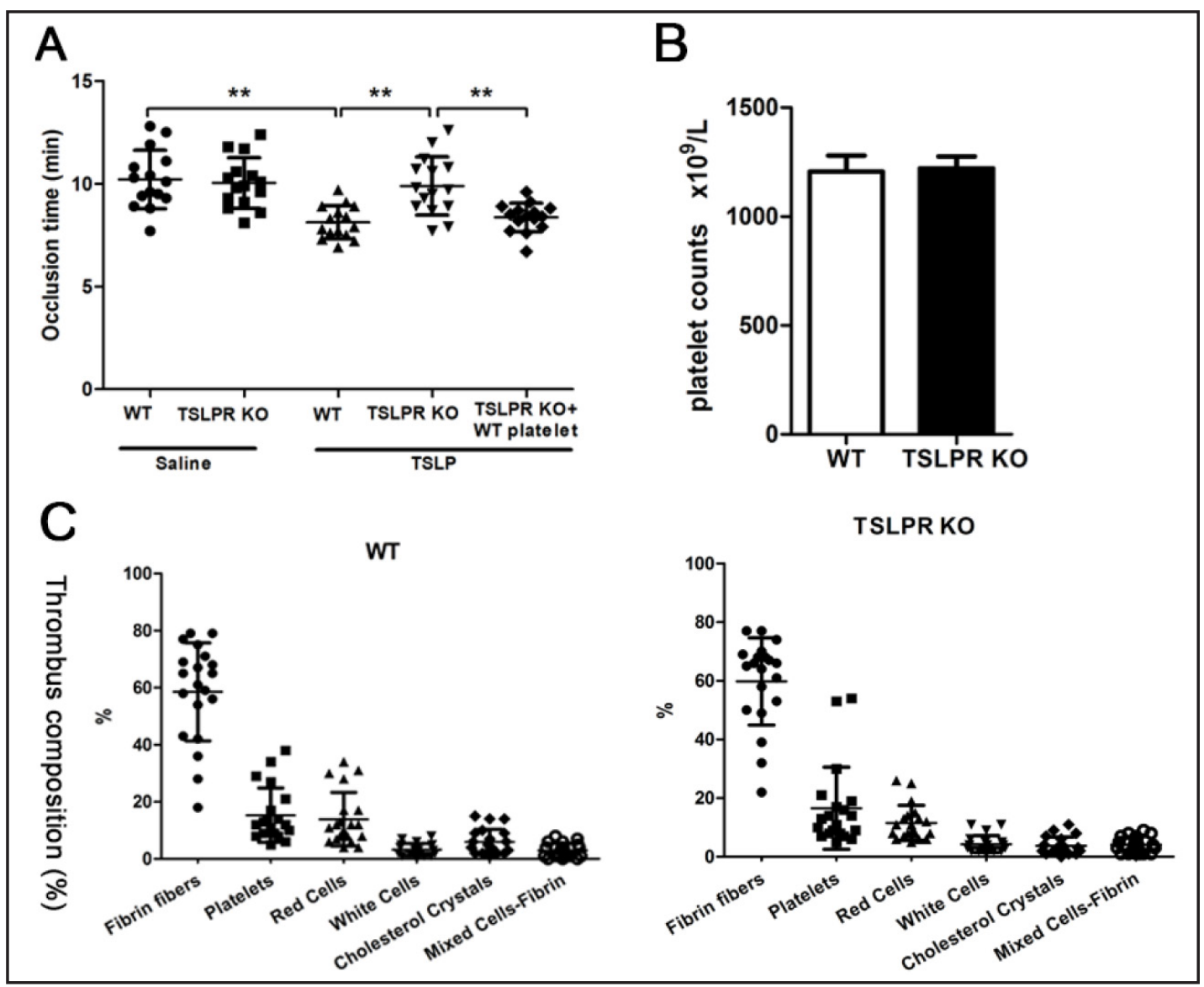

Fig. 5. A. Thrombus formation in the carotid artery after $\mathrm{FeCl}_{3}$ treatment. Thrombus formation in the carotid artery after $\mathrm{FeCl}_{3}$ treatment. Mice were injected with saline or TSLP (200 ng/ml) prior to the initiation of carotid artery injury. Values represent the mean \pm SEM $(n=15) . * *(p<0.01)$ indicates a significant difference. B. Effects of TSLPR deficiency on platelet quantity. Blood from the retroorbital plexus was drawn directly into plastic tubes that contained EDTA, and the platelet counts were detected using an automated hematology analyzer (COULTER LH 750, BECKMAN). Values represent the mean \pm SEM $(n=10)$. $(P>0.05)$ compared with the WT. C. Effects of TSLPR deficiency on thrombus composition. Stable occlusive thrombi were collected following the complete cessation of blood flow, which remained for the 30-minute duration of the assay. There was no significant difference in thrombus composition in the TSLPR KO mice compared with the WT $(n=20),(P>0.05)$ compared with the WT.

with low dose ADP $(44.6 \pm 11.8$ vs. $21.1 \pm 6.8, \mathrm{p}<0.01)$ or low dose thrombin $(47.7 \pm 5.8$ vs. $24.0 \pm 7.6, p<0.01$ ); this effect was not identified after stimulation with high dose ADP (Fig. 3 C,D). Thus, TSLP can directly interact with platelets and plays a stimulatory role that synergizes with low concentrations of platelet agonists to induce platelet aggregation.

\section{Effects of TSLP on platelet dense granule secretion}

Platelet secretion plays a critical role in the potentiation of platelet activation induced by low dose agonists. To determine whether platelet secretion accounted for the potentiating effect of TSLP on platelet aggregation, we examined TSLP-induced ATP release, which indicates the secretion of dense granules in human platelets. TSLP alone is sufficient to induce the release of ATP (ATP concentrations were $451.2 \pm 51.9 \mathrm{nmol} / \mathrm{L}$ (basal level) versus $657.8 \pm 72.4 \mathrm{nmol} / \mathrm{L}$ for TSLP.) (Fig. $3 \mathrm{E}$ ); however, the amount of ATP release induced by TSLP alone stimulation was substantially lower than the release induced by platelet agonists, such as thrombin (thrombin, at $0.01 \mathrm{U} / \mathrm{ml}$, induced approximately 33-fold increase of ATP release compared with the basal level). 


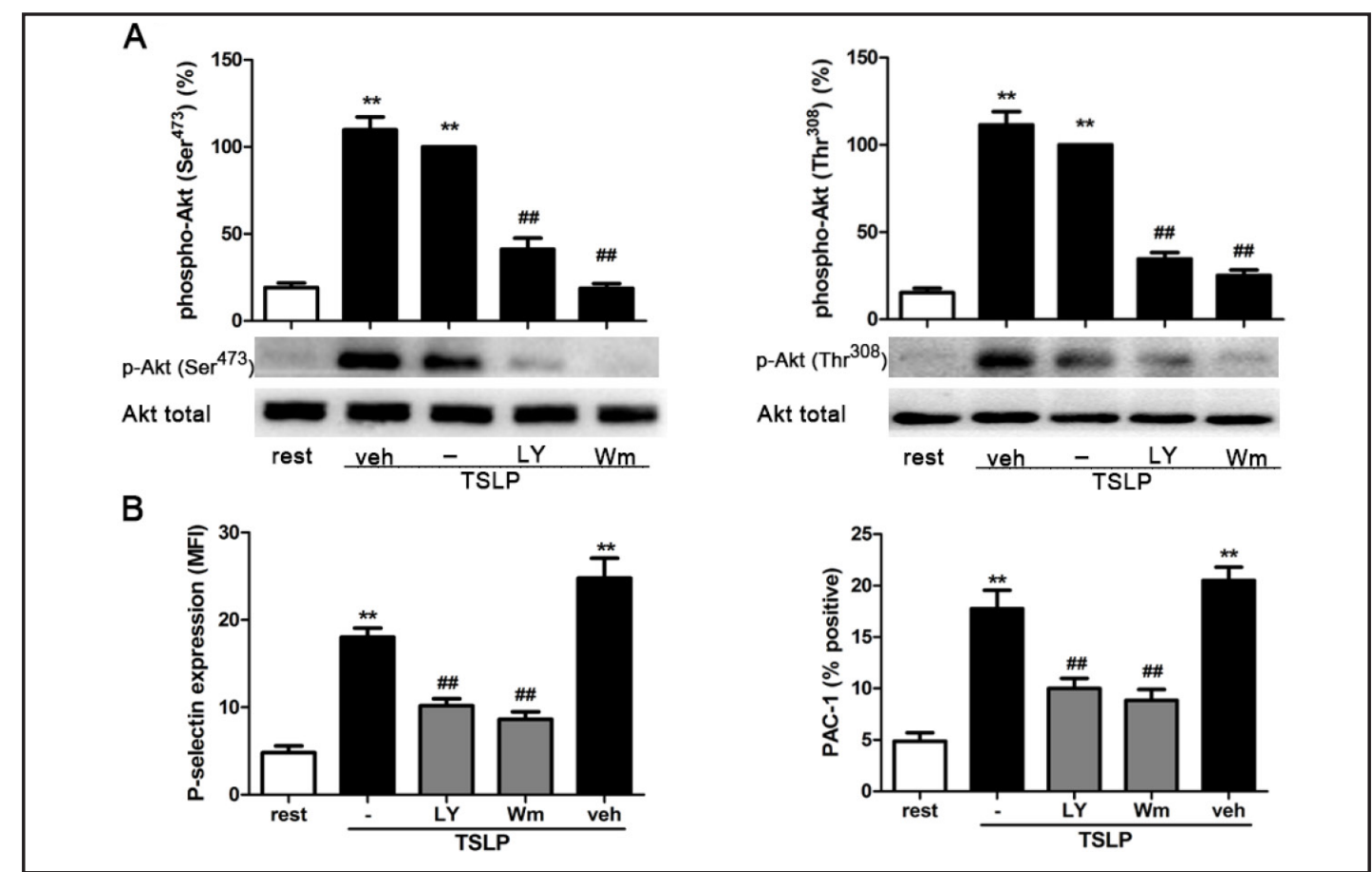

Fig. 6. Involvement of the PI3K/Akt pathway in TSLP-dependent platelet activation. A. Arithmetic means \pm SEM $(n=4)$ and representative western blot of Akt phosphorylation at Ser473 (left) and Thr308 (right) following stimulation with TSLP (200 ng/ml) in the presence or absence of the PI3K inhibitors LY294002 (LY, $25 \mu \mathrm{M}$ ) (Cayman Chemical) and Wortmannin (Wm, $100 \mathrm{nM}$ ) (Cayman Chemical). DMSO (vehicle) was added as a solvent control. ${ }^{* *}(\mathrm{p}<0.01)$ indicates a significant difference compared with the resting platelets, \#\# $(\mathrm{p}<0.01)$ compared with the TSLP-stimulated platelets in the absence of a PI3K inhibitor. B. Arithmetic means \pm SEM $(n=8)$ of flow cytometry of P-selectin (left) and activated integrin $\alpha$ IIb $\beta 3$ (PAC- 1 ; right) expression in platelets after stimulation with TSLP $(200 \mathrm{ng} / \mathrm{ml})$ in the presence or absence of LY $(25 \mu \mathrm{M}), \mathrm{Wm}$ $(100 \mathrm{nM})$ or DMSO (vehicle) as the solvent control. ${ }^{* *}(\mathrm{p}<0.01)$ indicates a significant difference compared with the resting platelets, \#\# ( $<<0.01)$ compared with the TSLP-stimulated platelets in the absence of a PI3K inhibitor.

Effects of TSLPR deficiency on platelet aggregation, secretion and in vitro thrombus formation

To evaluate whether the absence of TSLPR affected platelet function, we employed the platelet aggregometry and the perfusion chamber model. TSLPR KO platelets exhibited a markedly defective aggregation following stimulation with low dose thrombin compared with WT platelets (47.0 \pm 8.2 vs. $64.2 \pm 8.1, \mathrm{p}<0.01)$. Platelet aggregation exhibited a $25 \%$ reduction in the TSLPR KO relative to WT platelets (Fig. 4 A, B). Consistent with platelet aggregation, platelet serotonin release was significantly reduced in the TSLPR KO platelets in response to low dose thrombin ( $41.2 \pm 8.0$ vs. $28.9 \pm 7.1$, p<0.05) (Fig. 4 C). To assess the effects of TSLPR deficiency on platelet thrombus formation under flow conditions, we performed perfusion experiments that used glass coverslips coated with type I collagen fibrils. Consistent with the data from the in vitro platelet aggregation, in this ex vivo experiment, we observed significantly defective thrombus formation in the TSLPR KO mouse stimulation with TSLP at both low $\left(600 \mathrm{~s}^{-1}\right)$ and high $\left(1800 \mathrm{~s}^{-1}\right)$ shear rates compared with the WT mice (Fig. 4D).

Effects of TSLPR deficiency on FeCl3-induced carotid artery thrombosis

To evaluate whether the absence of TSLPR affected thrombus formation in the carotid artery, we employed the ferric chloride carotid artery thrombosis model. We demonstrated that TSLP stimulation shortened the vessel occlusion time of the WT mice. Following 

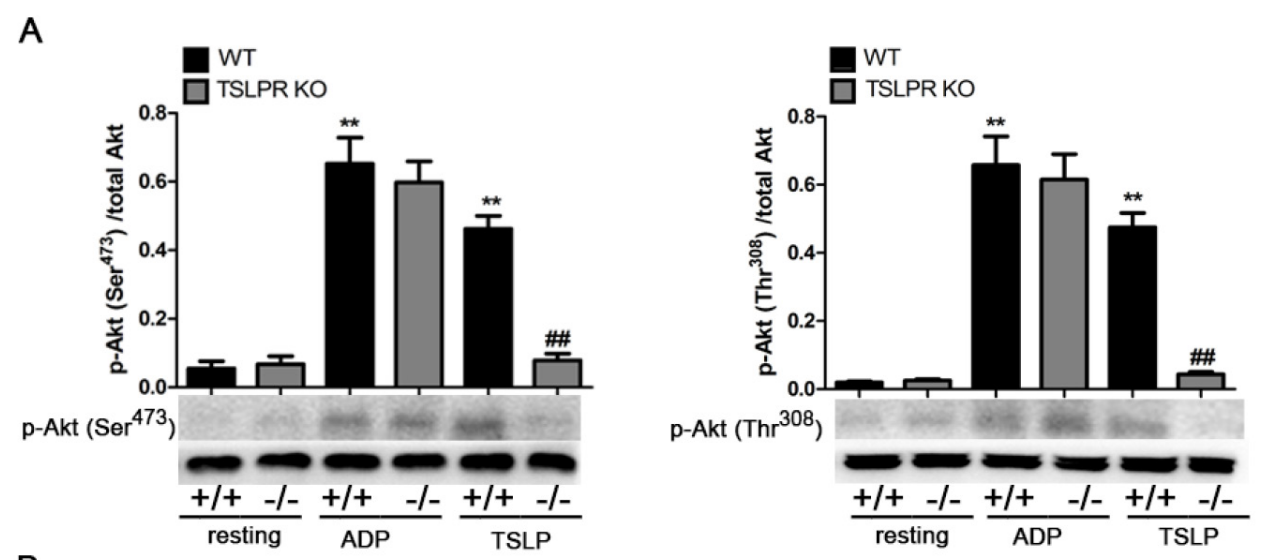

B
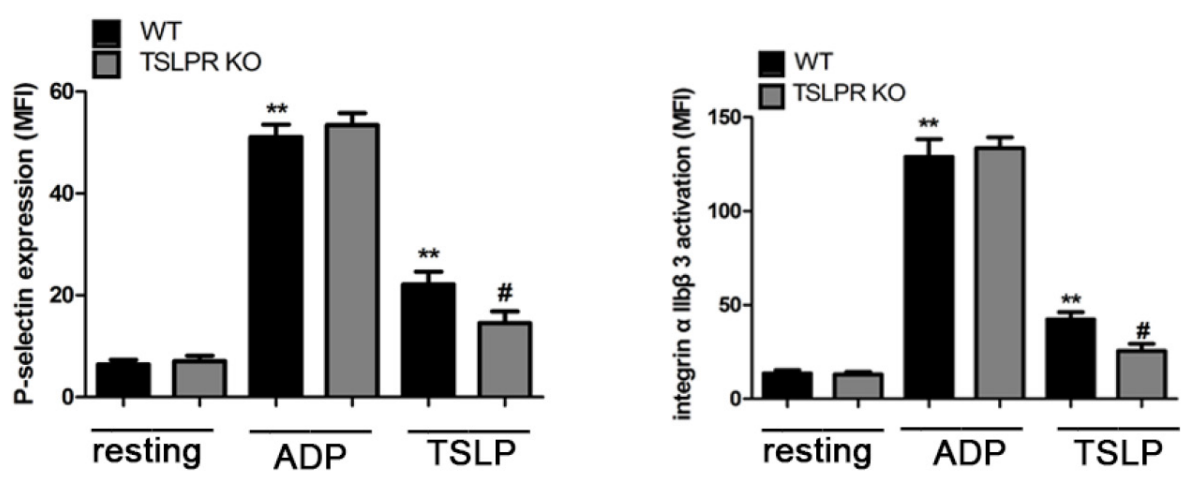

Fig. 7. TSLPR-dependency of TSLP-induced platelet Akt phosphorylation and activation. A. Arithmetic means \pm SEM ( $\mathrm{n}=4)$ and representative western blot of Akt phosphorylation at Ser473 (left) and Thr308 (right) in WT (black bars) and TSLPR KO (grey bars) platelets after stimulation with TSLP (200 ng/ml) or ADP $(10 \mu \mathrm{M}){ }^{* *}(\mathrm{p}<0.01)$ indicates a significant difference compared with the resting WT platelets, $\# \#(\mathrm{p}<0.01)$ compared with the TSLP-stimulated WT platelets. B. Arithmetic means \pm SEM $(n=8)$ of flow cytometry of Pselectin expression (left) and integrin $\alpha \mathrm{IIb} \beta 3$ activation (right) in WT (black bars) and TSLPR KO (grey bars) platelets after stimulation with TSLP $(200 \mathrm{ng} / \mathrm{ml})$ or ADP $(10 \mu \mathrm{M}) .{ }^{* *}(\mathrm{p}<0.01)$ indicates a significant difference compared with the resting WT platelets, $\#(p<0.05)$ compared with the TSLP-stimulated WT platelets.

stimulation with TSLP, compared with the WT mice, we determined that the vessel occlusion time was significantly delayed in the TSLPR KO mice $(P<0.01)$, but the occlusion times were not significantly different in the TSLPR KO mice plus WT washed platelet transfusion group $(P>0.05)$ (Fig. $5 \mathrm{~A})$.

\section{Involvement of the PI3K/Akt pathway in TSLP-dependent platelet activation.}

To determine whether TSLP affected platelet function through the PI3K/Akt signaling pathway, we detected the platelet p-Akt levels following stimulation with thrombin. In the western blot analysis, TSLP significantly increased Akt phosphorylation at Thr308 and Ser473, which could be prevented by preincubation with the PI3K inhibitors wortmannin $(100 \mathrm{nM})$ and LY294002 (25 $\mu \mathrm{M})$ (Fig. 6A). Consistent with these findings, the effects of TSLP on platelet activation (e.g., degranulation and integrin $\alpha \operatorname{Ilb} \beta 3$ activation) were abolished after preincubation with the PI3K inhibitors wortmannin (P-selectin: $18.1 \pm 2.9$ vs. $8.6 \pm 2.4$, $\mathrm{p}<0.01$; PAC-1: $17.8 \pm 5.1$ vs. 8.9 $\pm 3.0, \mathrm{p}<0.01$ ) and LY294002 (P-selectin: $18.1 \pm 2.9$ vs. 10.2 \pm 2.2 , $\mathrm{p}<0.01$; PAC-1: $17.8 \pm 5.1$ vs. $10.0 \pm 2.8$, p $<0.01$ ) (Fig. 6 B).

TSLPR-dependency of TSLP-induced platelet Akt phosphorylation and activation.

To determine if the effects of TSLP on platelet activation were attributed to the activation and downstream signaling of its receptor TSLPR, we analyzed TSLP-dependent platelet 
degranulation and integrin $\alpha \mathrm{IIb} \beta 3$ activation, as well as Akt phosphorylation in WT and TSLPR KO platelets (Fig. 7). As shown in Fig. 7 A, TSLP-dependent Akt phosphorylation was abrogated in the TSLPR KO platelets compared with the WT platelets. Thus, TSLP-induced platelet degranulation $(22.2 \pm 7.1$ vs. $14.5 \pm 6.5$, $\mathrm{p}<0.05)$ and integrin $\alpha \operatorname{IIb} \beta 3$ activation $(42.3$ \pm 11.0 vs. $25.6 \pm 10.6$, $\mathrm{p}<0.05$ ) were significantly reduced in the TSLPR KO platelets compared with the WT platelets, whereas ADP-dependent platelet activation was unaffected (Fig. 7B).

\section{Discussion}

Although there have been numerous studies examining the effects of TSLP in allergies and inflammation, TSLP may play a role not only in allergic disease but also in other diseases. Although classified as a hematopoietin receptor based on its structural homology, the TSLPR subunit contains notable differences compared with the canonical hematopoietin receptors. Our previous study demonstrated that the inflammatory cytokine TSLP was over-expressed in human atherosclerotic artery specimens [27].

T cells, B cells, basophils, monocytes, eosinophils, and DCs that are derived from the hematopoietic cells express functional TSLPRs [21,22]. Platelets are also derived from the megakaryocytes of hematopoietic cells. Whether platelets also express TSLPR is unknown. Whether platelets express functional TSLPR and whether the inflammatory cytokine TSLP plays a role in platelet function are completely unknown.

Our previous study demonstrated that the TSLPR was expressed on human platelets [34]. Our data demonstrated that the TSLPR was expressed on murine platelets (Fig. 1). Therefore, it is important to further examine the effects of TSLP/TSLPR on platelet function. We determined whether TSLP/TSLPR could alter platelet aggregation and secretion, as well as in thrombosis models in vitro and in vivo.

Platelets can sense different signals during activation and selectively release their granules, such as P-selectin. P-selectin may translocate to the cell surface when platelets are activated. Platelet activation also results in the conversion of $\alpha$ IIb $\beta 3$ integrin to an active conformation, which enables it to bind ligands, including fibrinogen and other proteins. The translocation and conformational changes of these proteins after platelet activation facilitates the interactions of platelets with their environment, which are important processes for hemostasis and thrombosis, as well as inflammation and atherosclerosis. We therefore measured the $\alpha$-granule secretion marker (P-selectin) and integrin $\alpha \operatorname{Ilb} \beta 3$. Our data demonstrated that TSLP increased the expression of P-selectin and activated integrin $\alpha \operatorname{IIb} \beta 3$ (Fig. $2 \mathrm{~A}, \mathrm{~B}$ ), whereas the quantity of the expression was minimal. The finding that TSLP induces the activation (degranulation and integrin $\alpha \operatorname{Ilb} \beta 3$ activation) of circulating platelets, which, in turn, could promote the release of platelet-derived inflammatory mediators that result in enhanced leukocyte recruitment [38], suggests a vicious circle that potentially aggravates the progression of atherogenesis.

Furthermore, the present study demonstrated that TSLP alone was unable to trigger potent aggregation of resting platelets; however, it significantly amplified platelet aggregation, P-selectin expression and integrin $\alpha \mathrm{IIb} \beta 3$ activation following stimulation with a low concentration of platelet agonists (Fig. 3). We proposed that TSLP potentiated platelet activation and exhibited a magnified effect via co-stimulation with platelet agonists. These data also indicated that TSLP and platelet agonists might use the same signaling pathway to promote platelet activation and aggregation.

TSLP alone is sufficient to induce the release of ATP; however, the amount of ATP release induced by TSLP stimulation is substantially lower compared with thrombin (Fig. 3 E). Similarly, TSLP alone induced P-selectin expression in human platelets, which indicates TSLP also stimulated a-granule secretion. Thus, TSLP stimulates platelet secretion of both dense and $\alpha$-granules and amplifies secretion-dependent platelet aggregation. The low level secretion and minimal activation of the integrin $\alpha \operatorname{Ib} \beta 3$ induced by TSLP stimulation may explain why TSLP alone induces a very low level of platelet aggregation.

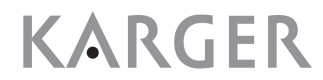


The TSLPR KO platelets exhibited a markedly defective aggregation response to thrombin compared with the WT platelets (Fig. 4 A, B). We also demonstrated that platelet serotonin release was markedly reduced in the TSLPR KO platelets response to thrombin (Fig. 4C). Aggregation and secretion defects at low concentrations of agonists for thrombin receptors are frequently indicative of a defect in secretion or secretory granule content.

Although platelet aggregometry is commonly employed to assess platelet function, it cannot be used to examine platelet aggregation under flowing, pathophysiological conditions. The perfusion chamber is an ex vivo model of thrombosis that has a number of important advantages over aggregometry, including the ability to assess thrombus formation on a pathophysiologically relevant substrate and under flow conditions with different shear stresses. Therefore, we employed the perfusion chamber model and monitored the effects of TSLPR deficiency on thrombus formation. We clearly demonstrated that thrombus formation was markedly decreased in the TSLPR KO mice at both low and high shear rates (Fig. 4D). These data suggest that TSLP/TSLPR may promote thrombosis at both venous and arterial shear rates. The late stages of atherosclerosis are often associated with thrombotic complications caused by vascular injury and compromised endothelial integrity [39]. To study the role of TSLP/TSLPR in the mediation of thrombus formation at the site of vascular injury using intravital microscopy, we observed defective thrombus formation in $\mathrm{FeCl}_{3}$-injured carotid arteries in TSLPR KO mice. To exclude the contribution of a TSLPR deficiency in the vessel wall, WT washed platelets were transfused into the TSLPR KO mice. We determined that the occlusion time clearly recovered. Compared with the WT mice, the occlusion time was not significantly different in the TSLPR KO mice plus WT platelet transfusion group (Fig. 5 A).

Some inflammatory cytokines can affect platelet count. Raffaele Strippoli et al. reported that IL-6-transgenic mice treated with lipopolysaccharide showed a quantitative difference in platelets compared with wild-type mice.[40] Regarding whether the absence of TSLPR affected the platelet quantity, our data demonstrated that there was no obvious difference in the platelet count in the TSLPR KO mice (Fig. 5B). Furthermore, we determined that there was also no significant difference in thrombus composition in the TSLPR KO mice (Fig. 5C). This observation indicates that defective thrombus formation is predominately because of a TSLPR deficiency on platelets.

Our results enable us to speculate that TSLP expression in atherosclerotic lesions and release from inflammatory cells could represent an additional local proadhesive stimulus for circulating platelets that results in increased platelet adhesion and aggregation at the sites of vascular injury. Therefore, data from our experiments in ex vivo perfusion chambers and the in vivo thrombosis models are consistent with our results from the in vitro platelet aggregation assays.

Our data demonstrated obviously defective expression of P-selectin and JON/A (activated integrin $\alpha I I b \beta 3$ ) in the TSLPR KO platelets after stimulation with TSLP compared with the WT (Fig. 7B). These data indicate that TSLP-dependent platelet activation critically depends on the binding to and signaling via the platelet TSLP receptor. Thus, we propose that the effects of TSLP/TSLPR on platelets may be to the result of the promotion of platelet activation, which subsequently increases platelet $\alpha$-granule release, as well as promotes integrin $\alpha \operatorname{IIb} \beta 3$ activation and ligand binding.

TSLP exerts broad and significant biological effects in various cell populations by binding to its receptors, which results in downstream signaling. However, TSLP-mediated cell signals remain poorly defined because their effects vary greatly between cell types. It has been demonstrated that the activation of the PI3K/Akt pathway occurred following TSLP stimulation $[32,33]$. Therefore, we conclude that TSLP stimulates platelets via the PI3K/AKT pathway. PI3K, as well as its downstream effector Akt play a decisive role in the regulation of platelet function [41]. PI3K synthesizes D3-phosphoinositides, which regulate many important platelet responses, such as platelet shape changes, integrin $\alpha \operatorname{IIb} \beta 3$ activation, and irreversible platelet aggregation $[42,43]$. Akt phosphorylation appears to function to direct irreversible platelet aggregation via the modulation of the continued activation of $\alpha \operatorname{IIb} \beta 3$ [44]. In addition, multiple agonists are known to stimulate PI3K in platelets, which 
subsequently activates Akt via phosphorylation [45].

Both Thr308 and Ser473 phosphorylation are required for full enzymatic activity [46]. In the present study, we demonstrated that TSLP significantly increases Akt phosphorylation, an effect that was completely abrogated in TSLPR-deficient platelets (Fig. 7A). This effect could also be observed in the preincubation of human platelets with LY294002 or wortmannin (Fig. 6 A). These results indicate that TSLP activates Akt in platelets in a TSLPR- and PI3Kdependent manner. Moreover, we identified a significant reduction of TSLP-induced platelet degranulation and integrin $\alpha \operatorname{IIb} \beta 3$ activation after preincubation with the PI3K inhibitors LY $(25 \mu \mathrm{M})$ and $\mathrm{Wm}(100 \mathrm{nM})$ (Fig. 6B). We also demonstrated that PI3K inhibitors could not completely down-regulate P-selectin expression and integrin activation. We suggest there may be other specific signaling pathways which require further investigated.

In conclusion, this study demonstrated that functional TSLPRs were expressed on murine platelets. TSLP triggered platelet TSLPR-dependent PI3K/Akt signaling, which led to degranulation and integrin $\alpha \operatorname{IIb} \beta 3$ activation. TSLP and platelet agonists via co-stimulation exhibited a magnified effect. We demonstrated that a TSLPR deficiency caused defective platelet aggregation and secretion and markedly attenuated thrombus growth in perfusion chambers at both low and high shear rates in the blood of TSLPR KO mice. TSLPR KO mice exhibited reduced carotid artery thrombus formation after exposure to $\mathrm{FeCl}_{3}$. Thus, the TSLP/TSLPR signaling system could play an important role in linking inflammatory vascular diseases and thrombosis.

\section{Acknowledgments}

We would like to thank Dr. Nicola L. Harris (Swiss Vaccine Research Institute) and Dr James N.Ihle (St. Jude Children's Research Hospital) for their Selfless offer TSLPR knockout mice. We thank Peige Zhang, Pei Zhang and Hongzhen Hao for expert technical assistance. This work was supported by National Natural Science Foundation of China to Dr. Dazhu Li (NO. 81170258).

\section{Disclosure Statement}

The authors declare that there is no conflict of interest.

\section{References}

1 Garcia A, Quinton TM, Dorsam RT, Kunapuli SP: Src family kinase-mediated and Erk-mediated thromboxane A2 generation are essential for VWF/GPIb-induced fibrinogen receptor activation in human platelets. Blood 2005;106:3410-3414.

- 2 Barrett NE, Holbrook L, Jones S, Kaiser WJ, Moraes LA, Rana R, Sage T, Stanley RG, Tucker KL, Wright B, Gibbins JM: Future innovations in anti-platelet therapies. Br J Pharmacol 2008;154:918-939. Ruggeri ZM: Platelets in atherothrombosis. Nat Med 2002;8:1227-1234.

Borst O, Schmidt EM, Munzer P, Schonberger T, Towhid ST, Elvers M, Leibrock C, Schmid E, Eylenstein A, Kuhl D, May AE, Gawaz M, Lang F: The serum- and glucocorticoid-inducible kinase 1 (SGK1) influences platelet calcium signaling and function by regulation of Orai1 expression in megakaryocytes. Blood 2012;119:251-261.

5 Varga-Szabo D, Braun A, Nieswandt B: Calcium signaling in platelets. J Thromb Haemost 2009;7:10571066.

6 Langer HF, Choi EY, Zhou H, Schleicher R, Chung KJ, Tang Z, Gobel K, Bdeir K, Chatzigeorgiou A, Wong C, Bhatia S, Kruhlak MJ, Rose JW, Burns JB, Hill KE, Qu H, Zhang Y, Lehrmann E, Becker KG, Wang Y, Simon DI, Nieswandt B, Lambris JD, Li X, Meuth SG, Kubes P, Chavakis T: Platelets contribute to the pathogenesis of experimental autoimmune encephalomyelitis. Circ Res 2012;110:1202-1210. 
Dong et al.: TSLP Triggers Platelet Activation

7 Gawaz M, Langer H, May AE: Platelets in inflammation and atherogenesis. J Clin Invest 2005;115:33783384.

8 May AE, Seizer P, Gawaz M: Platelets: inflammatory firebugs of vascular walls. Arterioscler Thromb Vasc Biol 2008;28:s5-s10.

-9 Ait-Oufella H, Taleb S, Mallat Z, Tedgui A: Recent advances on the role of cytokines in atherosclerosis. Arterioscler Thromb Vasc Biol 2011;31:969-979.

10 Zhang S, Yuan J, Yu M, Fan H, Guo ZQ, Yang R, Guo HP, Liao YH, Wang M: IL-17A facilitates platelet function through the ERK2 signaling pathway in patients with acute coronary syndrome. PLoS One 2012;7:e40641.

11 Thacker SG, Zhao W, Smith CK, Luo W, Wang H, Vivekanandan-Giri A, Rabquer BJ, Koch AE, Pennathur S, Davidson A, Eitzman DT, Kaplan MJ: Type I interferons modulate vascular function, repair, thrombosis, and plaque progression in murine models of lupus and atherosclerosis. Arthritis Rheum 2012;64:2975-2985.

$\$ 12$ Friend SL, Hosier S, Nelson A, Foxworthe D, Williams DE, Farr A: A thymic stromal cell line supports in vitro development of surface IgM+ B cells and produces a novel growth factor affecting B and T lineage cells. Exp Hematol 1994;22:321-328.

13 Sims JE, Williams DE, Morrissey PJ, Garka K, Foxworthe D, Price V, Friend SL, Farr A, Bedell MA, Jenkins NA, Copeland NG, Grabstein K, Paxton RJ: Molecular cloning and biological characterization of a novel murine lymphoid growth factor. J Exp Med 2000;192:671-680.

14 Soumelis V, Reche PA, Kanzler H, Yuan W, Edward G, Homey B, Gilliet M, Ho S, Antonenko S, Lauerma A, Smith K, Gorman D, Zurawski S, Abrams J, Menon S, McClanahan T, de Waal-Malefyt RR, Bazan F, Kastelein RA, Liu YJ: Human epithelial cells trigger dendritic cell mediated allergic inflammation by producing TSLP. Nat Immunol 2002;3:673-680.

15 Watanabe N, Hanabuchi S, Soumelis V, Yuan W, Ho S, de Waal MR, Liu YJ: Human thymic stromal lymphopoietin promotes dendritic cell-mediated CD4+ T cell homeostatic expansion. Nat Immunol 2004;5:426-434.

16 Nagarkar DR, Poposki JA, Comeau MR, Biyasheva A, Avila PC, Schleimer RP, Kato A: Airway epithelial cells activate TH2 cytokine production in mast cells through IL-1 and thymic stromal lymphopoietin. J Allergy Clin Immunol 2012;130:225-232.

17 Omori M, Ziegler S: Induction of IL-4 expression in CD4(+) T cells by thymic stromal lymphopoietin. J Immunol 2007;178:1396-1404.

18 Rochman I, Watanabe N, Arima K, Liu YJ, Leonard WJ: Cutting edge: direct action of thymic stromal lymphopoietin on activated human CD4+ T cells. J Immunol 2007;178:6720-6724.

19 Ying S, O'Connor B, Ratoff J, Meng Q Mallett K, Cousins D, Robinson D, Zhang G, Zhao J, Lee TH, Corrigan C: Thymic stromal lymphopoietin expression is increased in asthmatic airways and correlates with expression of Th2-attracting chemokines and disease severity. J Immunol 2005;174:8183-8190.

20 Ziegler SF: The role of thymic stromal lymphopoietin (TSLP) in allergic disorders. Curr Opin Immunol 2010;22:795-799.

21 Ziegler SF, Artis D: Sensing the outside world: TSLP regulates barrier immunity. Nat Immunol 2010;11:289-293.

-22 Reardon C, Lechmann M, Brustle A, Gareau MG, Shuman N, Philpott D, Ziegler SF, Mak TW: Thymic stromal lymphopoetin-induced expression of the endogenous inhibitory enzyme SLPI mediates recovery from colonic inflammation. Immunity 2011;35:223-235.

23 Demehri S, Turkoz A, Manivasagam S, Yockey LJ, Turkoz M, Kopan R: Elevated epidermal thymic stromal lymphopoietin levels establish an antitumor environment in the skin. Cancer Cell 2012;22:494-505.

-24 Hartgring SA, Willis CR, Dean CJ, Broere F, van Eden W, Bijlsma JW, Lafeber FP, van Roon JA: Critical proinflammatory role of thymic stromal lymphopoietin and its receptor in experimental autoimmune arthritis. Arthritis Rheum 2011;63:1878-1887.

25 Kaur D, Doe C, Woodman L, Wan WY, Sutcliffe A, Hollins F, Brightling C: Mast cell-airway smooth muscle crosstalk: the role of thymic stromal lymphopoietin. Chest 2012;142:76-85.

-26 Zhao H, Li M, Wang L, Su Y, Fang H, Lin J, Mohabeer N, Li D: Angiotensin II induces TSLP via an AT1 receptor/NF-KappaB pathway, promoting Th17 differentiation. Cell Physiol Biochem 2012;30:1383-1397.

27 Lin J, Chang W, Dong J, Zhang F, Mohabeer N, Kushwaha KK, Wang L, Su Y, Fang H, Li D: Thymic stromal lymphopoietin over-expressed in human atherosclerosis: potential role in Th17 differentiation. Cell Physiol Biochem 2013;31:305-318. 


\section{Cellular Physiology $\quad$ Cell Physiol Biochem 2015;35:160-174 and Biochemistry \\ Dong et al.: TSLP Triggers Platelet Activation}

28 Johansson MW, Han ST, Gunderson KA, Busse WW, Jarjour NN, Mosher DF: Platelet activation, P-selectin, and eosinophil $\beta 1$-integrin activation in asthma. Am J Respir Crit Care Med 2012;185:498-507.

29 Page C, Pitchford S: Platelets and allergic inflammation. Clin Exp Allergy 2014;44:901-913.

-30 Potaczek DP: Links between allergy and cardiovascular or hemostatic system. Int J Cardiol 2014;170:278285.

- 31 Benton AS, Kumar N, Lerner J, Wiles AA, Foerster M, Teach SJ, Freishtat RJ: Airway platelet activation is associated with airway eosinophilic inflammation in asthma. J Investig Med 2010;58:987-990.

-32 Rochman Y, Leonard WJ: The role of thymic stromal lymphopoietin in CD8+ T cell homeostasis. J Immunol 2008;181:7699-7705.

33 Ohba T, Haro H, Ando T, Koyama K, Hatsushika K, Suenaga F, Ohnuma Y, Nakamura Y, Katoh R, Ogawa H, Hamada Y, Nakao A: A potential role of thymic stromal lymphopoietin in the recruitment of macrophages to mouse intervertebral disc cells via monocyte chemotactic protein 1 induction: implications for herniated discs. Arthritis Rheum 2008;58:3510-3519.

34 Wang B, Peng Y, Dong J, Lin J, Wu C, Su Y, Fang H, Wang L, Huang K, Li D: Human platelets express functional thymic stromal lymphopoietin receptors: a potential role in platelet activation in acute coronary syndrome. Cell Physiol Biochem 2013;32:1741-1750.

- 35 Stellos K, Langer H, Daub K, Schoenberger T, Gauss A, Geisler T, Bigalke B, Mueller I, Schumm M, Schaefer I, Seizer P, Kraemer BF, Siegel-Axel D, May AE, Lindemann S, Gawaz M: Platelet-derived stromal cell-derived factor-1 regulates adhesion and promotes differentiation of human CD34+ cells to endothelial progenitor cells. Circulation 2008;117:206-215.

-36 Reheman A, Yang H, Zhu G, Jin W, He F, Spring CM, Bai X, Gross PL, Freedman J, Ni H: Plasma fibronectin depletion enhances platelet aggregation and thrombus formation in mice lacking fibrinogen and von Willebrand factor. Blood 2009;113:1809-1817.

- 37 Woulfe D, Jiang H, Morgans A, Monks R, Birnbaum M, Brass LF: Defects in secretion, aggregation, and thrombus formation in platelets from mice lacking Akt2. J Clin Invest 2004;113:441-450.

38 Huo Y, Schober A, Forlow SB, Smith DF, Hyman MC, Jung S, Littman DR, Weber C, Ley K: Circulating activated platelets exacerbate atherosclerosis in mice deficient in apolipoprotein E. Nat Med 2003;9:61-67.

-39 Lambert MP, Sachais BS, Kowalska MA: Chemokines and thrombogenicity. Thromb Haemost 2007;97:722729.

40 Strippoli R, Carvello F, Scianaro R, De Pasquale L, Vivarelli M, Petrini S, Bracci-Laudiero L, De Benedetti F: Amplification of the response to Toll-like receptor ligands by prolonged exposure to interleukin-6 in mice: implication for the pathogenesis of macrophage activation syndrome. Arthritis Rheum 2012;64:16801688.

41 Stojanovic A, Marjanovic JA, Brovkovych VM, Peng X, Hay N, Skidgel RA, Du X: A phosphoinositide 3-kinaseAKT-nitric oxide-cGMP signaling pathway in stimulating platelet secretion and aggregation. J Biol Chem 2006;281:16333-16339.

-42 Kovacsovics TJ, Bachelot C, Toker A, Vlahos CJ, Duckworth B, Cantley LC, Hartwig JH: Phosphoinositide 3-kinase inhibition spares actin assembly in activating platelets but reverses platelet aggregation. J Biol Chem 1995;270:11358-11366.

-43 Cosemans JM, Munnix IC, Wetzker R, Heller R, Jackson SP, Heemskerk JW: Continuous signaling via PI3K isoforms beta and gamma is required for platelet ADP receptor function in dynamic thrombus stabilization. Blood 2006;108:3045-3052.

-44 Romaniuk MA, Tribulatti MV, Cattaneo V, Lapponi MJ, Molinas FC, Campetella O, Schattner M: Human platelets express and are activated by galectin-8. Biochem J 2010;432:535-547.

45 Li Z, Zhang G, Le Breton GC, Gao X, Malik AB, Du X: Two waves of platelet secretion induced by thromboxane A2 receptor and a critical role for phosphoinositide 3-kinases. J Biol Chem 2003;278:3072530731.

46 Kim S, Jin J, Kunapuli SP: Akt activation in platelets depends on Gi signaling pathways. J Biol Chem 2004;279:4186-4195. 


\section{Erratum}

In the article by Dong et al., entitled "Inflammatory Cytokine TSLP Stimulates Platelet Secretion and Potentiates Platelet Aggregation via a TSLPR-Dependent PI3K/ Akt Signaling Pathway" [Cell Physiol Biochem 2015;35:160-174 (DOI: 10.1159/000369684)], is a printing error.

The first authors name was spelled as "Jangchuan Dong", the right spelling is "Jiangchuan Dong". 